\title{
Effect of Polyol Chain Length on Proton Relaxivity of Gadolinium Oxide Nanoparticles for Enhanced Magnetic Resonance Imaging Contrast
}

\author{
Anupam Guleria ${ }^{1 *}$, Pranjali ${ }^{1 \dagger}$, Mukesh Kumar Meher ${ }^{2 \dagger}$, Anamika Chaturvedii ${ }^{1 \dagger}$, Sreemoyee \\ Chakraborti $^{1}$, Ritu Raj ${ }^{1}$, Krishna Mohan Poluri ${ }^{2,3}$, and Dinesh Kumar ${ }^{1}$ \\ ${ }^{1}$ Centre of Biomedical Research, SGPGIMS Campus, Lucknow-226014, India \\ ${ }^{2}$ Department of Biotechnology, ${ }^{3}$ Centre for Nanotechnology, Indian Institute of Technology \\ Roorkee, Roorkee 247667, India
}

†Authors contributed equally.

\author{
* Author for correspondence: \\ Dr. Anupam Guleria \\ Centre of Biomedical Research (CBMR), \\ SGPGIMS Campus, \\ Raebareli Road, Lucknow-226014 \\ Uttar Pradesh, India \\ Email: anucbmr@gmail.com \\ Mobile: +91-9918004592
}




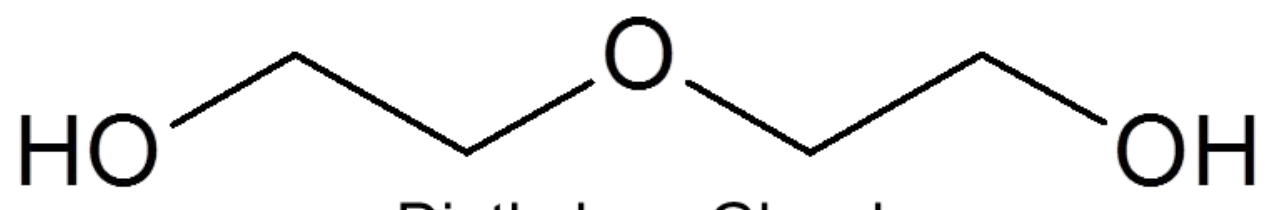

Diethylene Glycol<smiles>OCCOCCOCCO</smiles>

Triethylene Glycol<smiles>OCCOCCOCCOCCO</smiles>

Tetraethylene Glycol

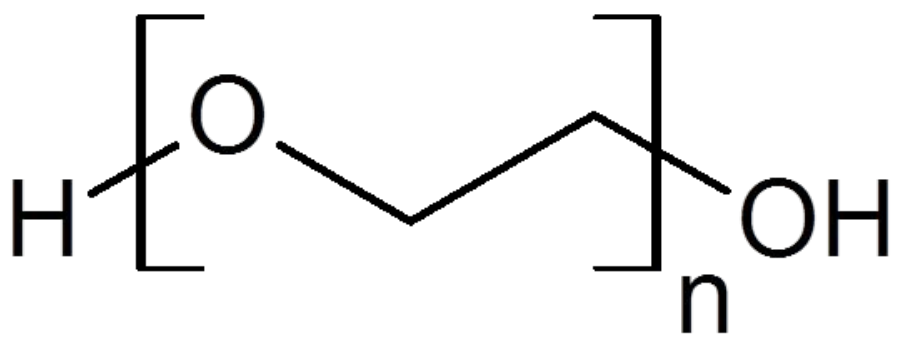

Polyethylene Glycol

Figure S1: Chemical structure of polyols used in the synthesis of $\mathrm{Gd}_{2} \mathrm{O}_{3}$ nanoparticles. 

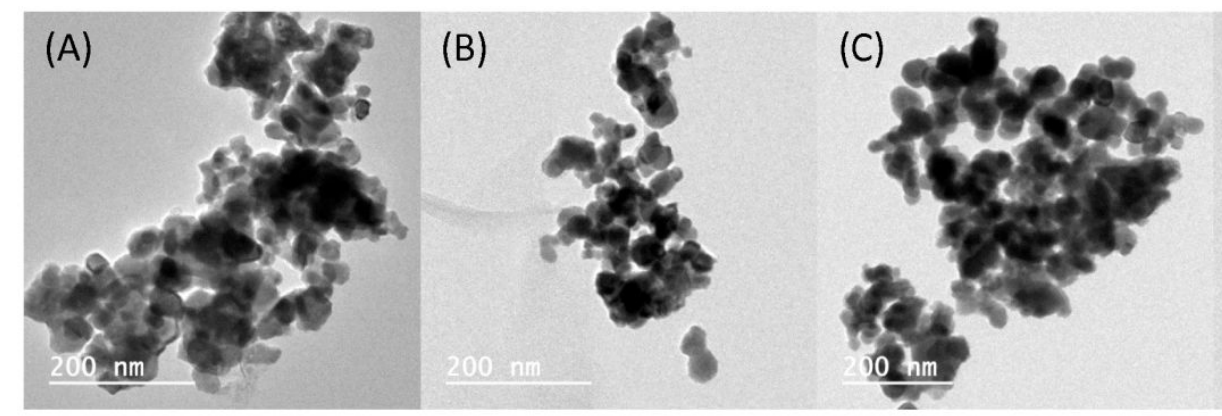

(D)
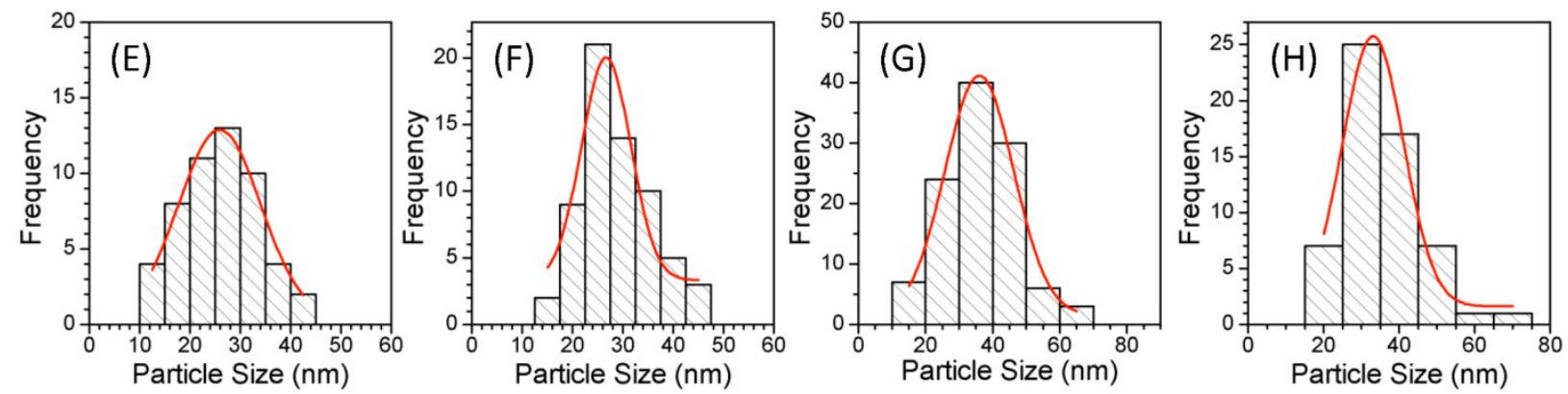

Figure S2: (A-D) TEM images and (E-H) corresponding size distribution histogram of calcinated DEG-, TEG-, TeEG-, and PEG-Gd $\mathrm{O}_{3}$ nanoparticles, respectively. Red solid lines are the Gaussian fitting to the distribution. 

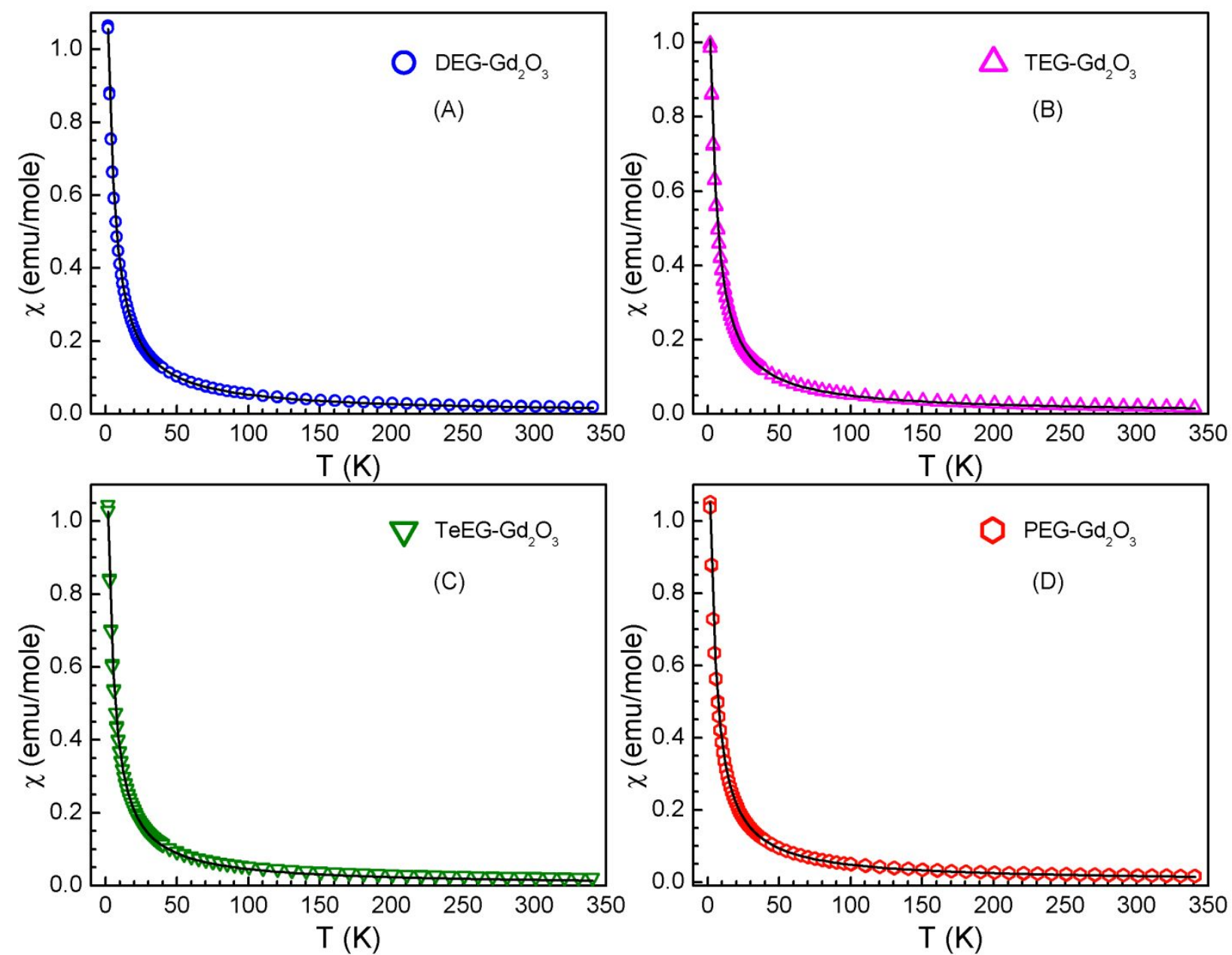

Figure S3: Temperature dependence of magnetic susceptibility for $\mathrm{Gd}_{2} \mathrm{O}_{3}$ nanoparticles synthesized in (A) Diethylene, (B) Triethylene, (C) Tetraethylene and (D) Polyethylene glycol. The solid lines in plots are the fit to Curie-Weiss equation $\chi=C /\left(T-\theta_{P}\right)$, where $C$ is the Curie constant and $\theta_{\mathrm{P}}$ is the Curie-Weiss temperature. 


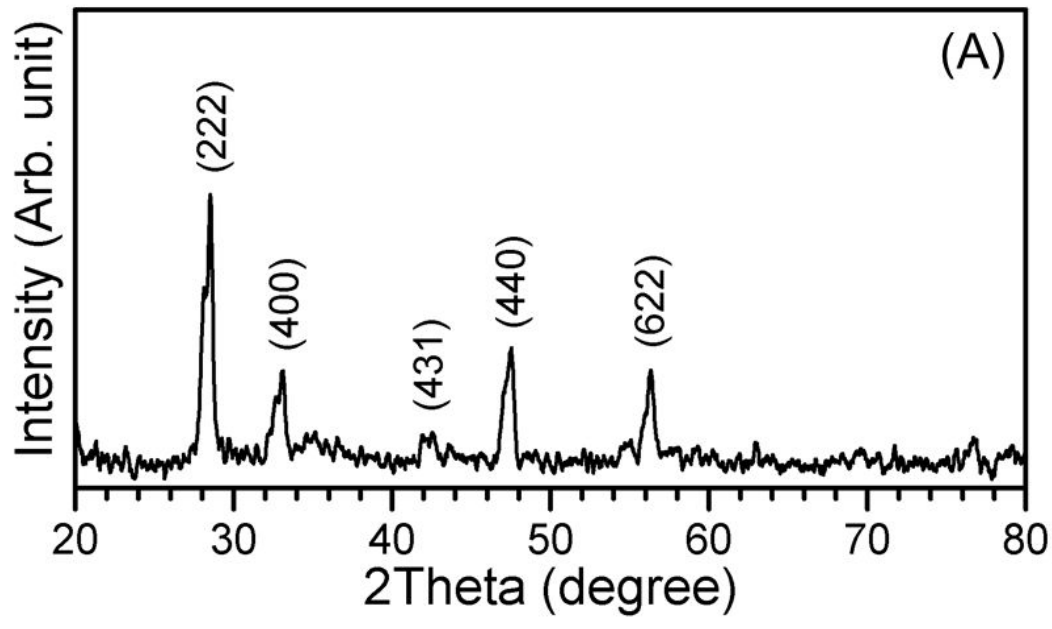

(B)

Figure S4: (A) X-ray diffraction pattern of bare $\mathrm{Gd}_{2} \mathrm{O}_{3}$ nanopowder and (B) corresponding TEM image.

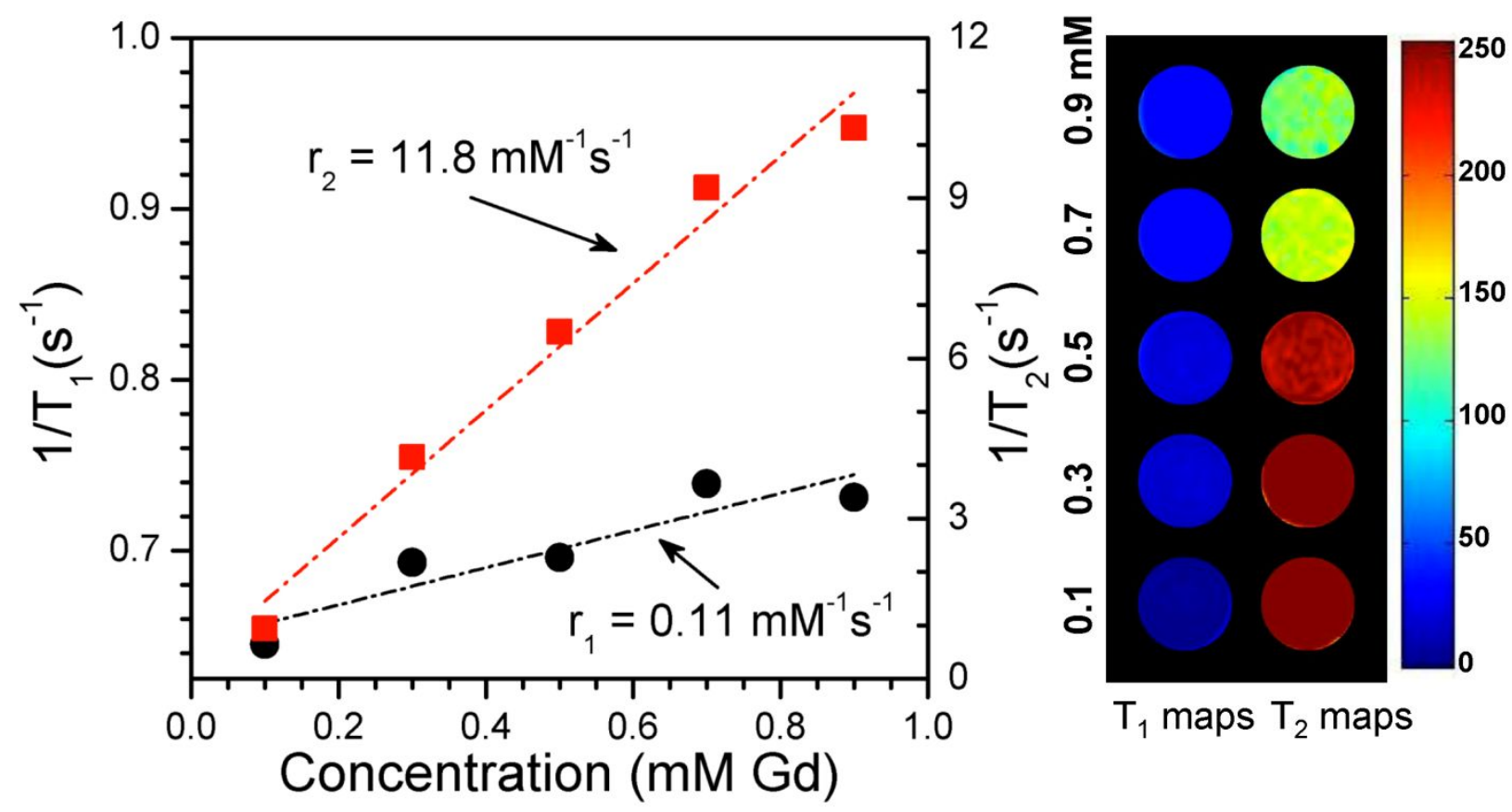

Figure S5: Plots of $T_{1}$ and $T_{2}$ based relaxation rates for bare $\mathrm{Gd}_{2} \mathrm{O}_{3}$ nanoparticles as a function of Gd concentration. The slopes correspond to $r_{1}$ and $r_{2}$ relaxivities, respectively. Color mapped $T_{1}$ and $\mathrm{T}_{2}$ weighted in vitro $\mathrm{MR}$ images of bare $\mathrm{Gd}_{2} \mathrm{O}_{3}$ nanoparticles in water with different $\mathrm{Gd}$ concentrations are also shown. 

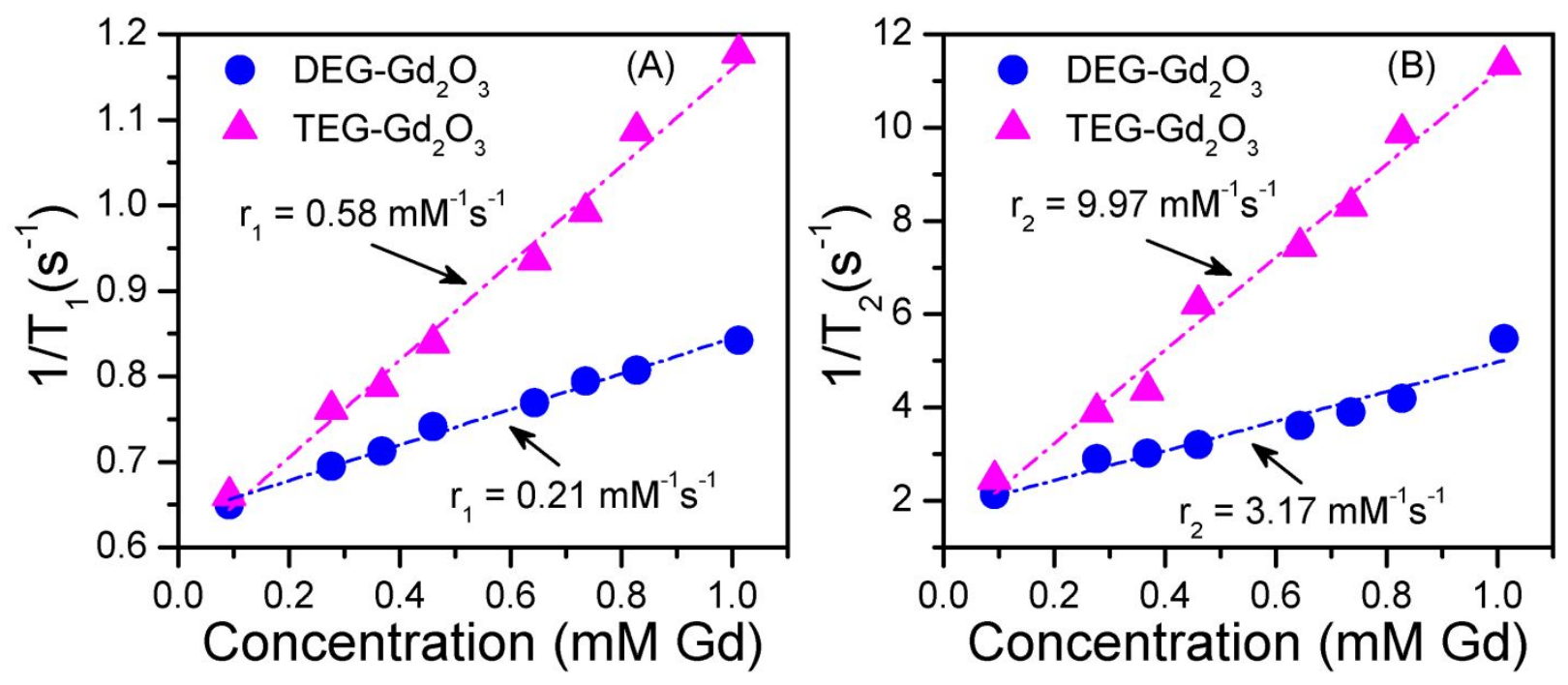

Figure S6: Plots of (A) $\mathrm{T}_{1}$ and (B) $\mathrm{T}_{2}$ based relaxation rates for calcined DEG- and TEG-Gd $\mathrm{O}_{3}$ nanoparticles (average particle size $\sim 26 \mathrm{~nm}$ ) as a function of $\mathrm{Gd}$ concentration. 